\title{
Brackiella oedipodis gen. nov., sp. nov., Gram- negative, oxidase-positive rods that cause endocarditis of cotton-topped tamarin (Saguinus oedipus)
}

\author{
${ }^{1}$ Laboratorium voor \\ Microbiologie, Faculteit \\ Wetenschappen, \\ Universiteit of Gent, K. L. \\ Ledeganckstraat 35, \\ B-9000 Gent, Belgium \\ 2 Deutsches \\ Primatenzentrum $\mathrm{GmbH}$, \\ Kellnerweg 4, D-37077 \\ Göttingen, Germany \\ 3 Robert Koch-Institut, \\ Wernigerode, Burgstr. 37, \\ D-38855 Wernigerode, \\ Germany \\ 4 Sächsische Landesanstalt \\ für Landwirtschaft, Gustav- \\ Kühn-Str. 8, D-04159 \\ Leipzig, Germany \\ 5 Robert Koch-Institut Berlin, \\ Nordufer 20, D-13353 \\ Berlin, Germany
}

\author{
Anne Willems, ${ }^{1}$ Helga Gilhaus, ${ }^{2}$ W. Beer, ${ }^{3}$ Henriette Mietke, ${ }^{4}$ \\ H. R. Gelderblom, ${ }^{5}$ Bärbel Burghardt, ${ }^{3}$ W. Voigt ${ }^{3}$ and R. Reissbrodt ${ }^{3}$
}

Author for correspondence: R. Reissbrodt. Tel: +49 3943679 258. Fax: +49 3943679207. e-mail: reissbrodtr@ rki.de

\begin{abstract}
A Gram-negative, oxidase-positive, rod-shaped bacterium isolated from the heart of a cotton-topped tamarin was characterized by 165 rDNA sequence analysis, SDS-PAGE of whole-cell proteins, fatty acid analysis and biochemical tests. Outer-membrane proteins, iron-regulated outer-membrane proteins, lipopolysaccharides and siderophore production were studied. On the basis of the results, the organism belongs to the $\beta$-Proteobacteria where it forms a separate line of descent, for which a novel genus and species are proposed,

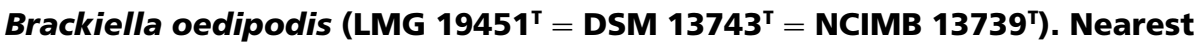
phylogenetic neighbours of the new genus are Taylorella, Pelistega, Bordetella, Alcaligenes and Achromobacter.
\end{abstract}

Keywords: Brackiella oedipodis gen. nov., sp. nov., new genus, endocarditis

\section{INTRODUCTION}

The German Primate Center Göttingen (GPC) was established in 1978 as a biomedical institute for research on non-human primates. The centre is also engaged in the breeding and preservation of certain highly endangered primate species that are not intended for experimental use. One of these endangered species is the cotton-topped tamarin (Saguinus oedipus), a small neotropical primate of approximately $300-400 \mathrm{~g}$ body mass. The natural habitat of this primate is in the secondary forests of north-western Colombia. Habitat destruction by extensive deforestation has resulted in the dramatic decline of the wild $S$. oedipodis populations.

Since 1978, the GPC has housed a colony of approximately 60 cotton-topped tamarins with satisfactory breeding success. The animals are kept strictly indoors in small family groups for breeding purposes. Cottontopped tamarins are very sensitive to outside influ-

\footnotetext{
Abbreviations: FT-IR spectra, Fourier-transform infrared spectra; IROMP, iron-regulated outer-membrane protein; LPS, lipopolysaccharide; OMP, outer-membrane protein.

The EMBL accession number for the 16S rDNA sequence of Brackiella oedipodis LMG $19451^{\top}$ is AJ277742.
}

ences; even minor environmental changes may cause transient diarrhoea. The most dramatic diseases of captive cotton-topped tamarins are mucoid colonic cancers and chronic colitis, both of unknown cause. Like all callitrichids, they are prone to mesangioproliferative nephropathies. Remarkable bacterial infections of the GPC cotton-topped tamarin colony in the past have been repeated clusters of Bordetella bronchiseptica bronchopneumonias, occasional Erysipelothrix rhusiopathiae septicaemias or Yersinia pseudotuberculosis intestinal infections.

During a routine post-mortem necropsy investigation of the heart of a cotton-topped tamarin, which had suddenly died during a tooth extraction, an unknown Gram-negative, oxidase-positive, rod-shaped bacterium was isolated. The captive-bred male tamarin had not previously displayed any obvious signs of disease when it died aged 10 years, 4 months and $12 \mathrm{~d}$. It had lived behind a barrier system at $25-27^{\circ} \mathrm{C}$ and $70 \%$ humidity and was fed on a diet of commercial marmoset pellets, enriched by cream cheese and a variety of fruits depending on the season. During its life, it suffered from several bouts of diarrhoea, common with all tamarins. When such infections were shown to be associated with Giardia lamblia or Campylobacter, they were successfully treated with 
antibiotics or probiotics (Symbioflor 1; Symbiopharm). The monkey sired several offspring, the last ones being $40 \mathrm{~d}$ before its sudden death.

The bacterium isolated from the heart tissue could not be assigned to any of the known bacterial species or genera. In this paper, isolation and characterization of this organism by $16 \mathrm{~S}$ rDNA analysis, analysis of whole-cell proteins by SDS-PAGE, fatty acid analysis, characterization of the outer-membrane proteins (OMPs), iron-regulated outer-membrane proteins (IROMPs) and siderophore production as well as lipopolysaccharides (LPSs) and Fourier-transform IR (FT-IR) spectra are reported. Based on these findings, creation of a novel genus and species for this organism, Brackiella oedipodis gen. nov., sp. nov., in the $\beta$ Proteobacteria is proposed.

\section{METHODS}

Isolation of the organism. Dissection of the dead cottontopped tamarin was performed immediately after its sudden death according to the standardized GPC protocol. In this case, bacteriological examination was limited to the heart only, because the abdominal cavity was opened without sterile precautions assuming an intestinal neoplastic condition from the colony and individual anamnesis. That assumption, however, was not confirmed by the necropsy results. Instead, at thoracotomy, cardiomegaly and chronic epicarditis were evident with at least the latter requiring bacteriological examination. The cardiac surface was heatsterilized immediately following thoracotomy, the left ventricle was opened using a sterile scalpel and a loop of cardiac blood was streaked onto the surface of a Columbia agar plate for initial cultivation and purification. Cultivation under aerobic conditions was at $37^{\circ} \mathrm{C}$ for $24 \mathrm{~h}$.

Bacterial strains. Achromobacter xylosoxidans subsp. xylosoxidans DSM 2402 ${ }^{\mathrm{T}}$, Alcaligenes defragrans DSM $12141^{\mathrm{T}}$, Bordetella avium DSM $11332^{\mathrm{T}}$, Bordetella parapertussis DSM $13415^{\mathrm{T}}$, Alcaligenes faecalis subsp. faecalis DSM $30030^{\mathrm{T}}$ and Taylorella equigenitalis DSM $10668^{\mathrm{T}}$ were purchased from the Deutsche Sammlung für Mikroorganismen und Zellkulturen (DSMZ), Braunschweig, Germany. The siderophore indicator strains Escherichia coli AB 2847, Salmonella typhimurium enb-7, E. coli LG 1522, Pseudomonas aeruginosa PAO 6609 and Microbacterium (formerly Aureobacterium) flavescens JG-9 were taken from the stock collection of the Robert Koch-Institut Wernigerode.

Bacterial growth and growth media. To examine bacterial growth, the isolate was inoculated onto and into different bacteriological growth media (e.g. tryptic soy agar, nutrient agar, sheep blood agar, tryptic soy broth) and incubated under various oxygen conditions (aerobic, microaerophilic, anaerobic) and at different temperatures between 4 and $42{ }^{\circ} \mathrm{C}$. The $\mathrm{pH}$ was maintained at $7 \cdot 0-7 \cdot 4$. Where other media were used for particular tests, these are listed with each test below.

Light microscopy. Overall cell morphology was examined by phase-contrast microscopy (Nikon Optiphot 2) with an oilimmersion objective lens and by Gram-staining.

Electron microscopy. After $2 \mathrm{~d}$ growth, a few colonies were removed from the surface of the blood agar plate and gently suspended in distilled water. Negative staining of the bacteria followed routine techniques using 400 mesh copper grids, covered with Pioloform, reinforced with a $15 \mathrm{~nm}$ layer of carbon and made hydrophilic before use by a glow discharge (Gelderblom et al., 1985). Cells were adsorbed from a $50 \mu$ droplet of the bacterial suspension on the grids and negatively contrasted using $1 \%$ uranyl acetate and evaluated at $80 \mathrm{kV}$ under a Zeiss EM 10 A transmission electron microscope. Measurements were made on the electron microscopy negatives using a 10 -fold magnifying lens.

Phenotypic characterization. Physiological and biochemical characteristics were investigated by classical methods (Murray et al., 1999; Vandamme et al., 1998) by the Biolog identification system (Micro-Station system release 3.50; GN MicroPlate) and by the 47 biochemical reactions of the Bactid-Identification system for Enterobacteriaceae kindly provided by J. J. Farmer, III, Centers for Diseases Control and Prevention, Atlanta, GA, USA. For all test systems, bacterial strains that are known to give either positive or negative reactions were included to verify test conditions. The tests were repeated at least twice.

Analysis of proteins by SDS-PAGE. Bacteria were grown on buffered nutrient agar at $37^{\circ} \mathrm{C}$ for $48 \mathrm{~h}$. Cellular protein extracts were prepared as described previously (Pot et al., 1994). SDS-PAGE, digitization, normalization and numerical analyses of the protein patterns were performed with GELCOMPAR 4.0 software (Applied Maths, Kortrijk, Belgium) as described by Pot et al. (1994).

Sequencing and phylogenetic analysis of the 16S rDNA. A large part (corresponding to positions 39-1521 of the E. coli rDNA) of the 16S rRNA gene sequences was amplified by PCR using conserved primers 5'-CTGGCTCAGGAYGAACGCTG (19-38) and 5'-AAGGAGGTGATCCAGCCGCA (1522-1541). The PCR product was purified using a Qiaquick PCR purification kit (Qiagen) and sequenced using conserved primers and a BigDye Dideoxy Terminator Cycle Sequencing kit (PE Biosystems) and an ABI 310 Genetic Analyzer (PE Biosystems) according to the manufacturer's instructions. The consensus sequence was constructed using the AUTOASSEMBLER software (PE Biosystems). A FASTA search was performed to identify the sequences most similar to the new data. Sequences of related taxa were retrieved from the EMBL database for comparison. Sequences were aligned using the program PILEUP of the GCG software (Devereux et al., 1984) and phylogenetic analyses were performed using the TREECON package (Van de Peer \& De Wachter, 1994). Distances were calculated using the Kimura correction and clustering was performed with the neighbourjoining algorithm. Bootstrap analysis was performed using 500 replications.

Siderophore production. Production of siderophores was verified by cross-feeding tests using the siderophore-indicator strains E. coli AB 2847 and S. typhimurium enb-7 (phenolate- and hydroxamate-type siderophores), E. coli LG 1522 (aerobactin), Pseudomonas aeruginosa PAO 6609 (phenolate- and hydroxamate-siderophores, pyoverdins, pyochelin) and $M$. flavescens JG-9 (hydroxamate-type siderophores, $\alpha$-keto- $/ \alpha$-hydroxy acids) according to Reissbrodt et al. (1993, 1997). A suspension of the isolate was ironstarved in Tris-succinate buffer, $\mathrm{pH} 7 \cdot 3$, and placed onto the surface of the controlled cross-feeding plates mentioned above. These plates were incubated at $30^{\circ} \mathrm{C}$ (M. flavescens JG-9, Pseudomonas aeruginosa PAO 6609) or at $37^{\circ} \mathrm{C}(E$. coli and $S$. typhimurium strains) for $48 \mathrm{~h}$ in a candle jar. 
Antibiotic susceptibility testing. The susceptibility of the isolate to antimicrobial agents (minimum inhibitory concentration) was investigated according the methodology of the National Committee for Clinical Laboratory Standards (1998).

Analysis of OMPs and IROMPs by SDS-PAGE. Bacteria were grown on tryptic soy agar (Becton-Dickinson) for OMP analysis and on the same medium containing $0.4 \mathrm{mM}$ ethylene-di-( $o$-hydroxyphenylacetic acid) for IROMP analysis at $37^{\circ} \mathrm{C}$ for $48 \mathrm{~h}$ in a candle jar. Protein extracts and SDS-PAGE were prepared according to Lugtenberg et al. (1975). The molecular mass standard was from the LMW electrophoresis kit 17-0446-01 (Amersham Pharmacia Biotech).

Analysis of LPS pattern. Bacteria were grown on tryptic soy agar at $37^{\circ} \mathrm{C}$ for $24 \mathrm{~h}$ and the LPS were isolated as described by Achtman et al. (1983). Electrophoresis was carried out according to Lugtenberg et al. (1975). Gels were stained with an alkaline $\mathrm{AgNO}_{3}$ solution according to Tsai \& Frasch (1982). Additionally, the gels were scanned using an imaging densitometer GS 700 (Bio-Rad) at $550 \mathrm{~nm}$.

Fatty acid profile. The isolate was grown on tryptic soy agar at $37^{\circ} \mathrm{C}$ for $24 \mathrm{~h}$. Bacterial cells (about $40 \mathrm{mg}$ ) were harvested from the third quadrant of a four quadrant streaking pattern with a $4 \mathrm{~mm}$ loop and placed in culture tubes. Saponification took place on heating in aqueous methanolic $15 \%$ sodium hydroxide, methylation in aqueous methanolic $6.0 \mathrm{M}$ hydrochloric acid and extraction in hexane/methyl tert-butyl ether according to the protocol given in Technical note 101 of the MIDI microbial identification system. GC was performed with a Hewlett-Packard HP5890A and an HP3392A integrator. Peaks were calibrated and named using the external calibration mixture HP 19298-60500 (Hewlett-Packard). Evaluation and matching were performed using the aerobe (TSBA) and the clinical aerobe database of the MIDI system (version 3.8).

FT-IR measurements. Bacteria were grown for $24 \mathrm{~h}$ at $37^{\circ} \mathrm{C}$ on caso agar plates (Merckoplate; Merck). From the confluent growth of the third quadrant of a four-quadrant streaking pattern, 1 loopful $(1 \mathrm{~mm}$ in diameter; $\sim 200 \mu \mathrm{g})$ was suspended in $80 \mu \mathrm{l}$ distilled water. A portion $(35 \mu \mathrm{l})$ of this suspension was transferred to a preformed sample area on a zinc selenite optical plate of a multisample cuvette and dried in vacuo at about $3.5 \mathrm{kPa}$ to get a transparent film. Spectra were taken at $4000-500 \mathrm{~cm}^{-1}$ using the FT-IR spectrometer IFS-28/B (Bruker) and recorded in absorbance units (A). A total of 128 interferograms per sample was added together and averaged for each spectrum. The spectral resolution was $6 \mathrm{~cm}^{-1}$. All recordings were performed using three individual samples and subsequently averaged after minimum-maximum normalization between 0 and $2 \mathrm{~A}$ of the spectra. Cluster analysis was performed using the first derivative. The specific information content in the spectral windows of $3000-2800 \mathrm{~cm}^{-1}$ [weighting $(\mathrm{W})=1 \cdot 0$; fatty acid region I], $1200-900 \mathrm{~cm}^{-1}(\mathrm{~W}=3 \cdot 0$; polysaccharide region $)$ and $900-700 \mathrm{~cm}^{-1}(\mathrm{~W}=1 \cdot 0$; true 'fingerprint' region) was used in 'Ward's' algorithm (Helm et al., 1991).

\section{RESULTS}

\section{Necropsy observations}

The most conspicuous finding at necropsy was a distinctively enlarged heart with left-sided dilatation and right-sided ventricular hypertrophy. Histopatho-

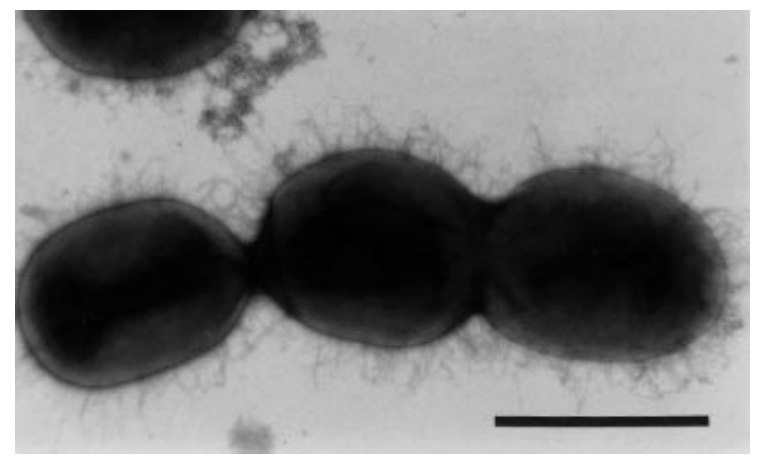

Fig. 1. Electron micrograph of the new isolate after negative staining showing coccoid cells without flagella surrounded by abundant fimbriae. Bar, $1 \mu \mathrm{m}$.

logically, this was seen as a diffuse, advanced chronicpurulent epicarditis and thrombo-embolic endocarditis. Cardiac lesions were accompanied by scattered alveolar heart-failure cells and a marked alveolar oedema of the lung. All other organic lesions (mesangioproliferative nephropathy, extramedullary haematopoiesis) were less conspicuous, since they are common in all Callitrichidae.

\section{Morphological and phenotypic characterization}

Cells were non-motile and appeared as Gram-negative coccoid rods by light microscopy. By transmission electron microscopy, individual cells appeared slightly ovoid and measured $0.9 \times 1.1 \mu \mathrm{m}$, whereas growing cells immediately before division measured up to $1.8 \mu \mathrm{m}$ in length. Bacteria did not show any flagella, but were surrounded by densely studded fimbriae $280 \mathrm{~nm}$ in length (Fig. 1).

The isolate grew on blood agar (e.g. tryptic soy agar with 5\% sheep blood) under aerobic conditions. Growth was better in a candle jar, but the isolate would not grow under anaerobic conditions. Growth was observed at incubation temperatures in the range $30-37^{\circ} \mathrm{C}$, but no growth was seen at 4,20 or $42^{\circ} \mathrm{C}$. After $24 \mathrm{~h}$ incubation, two types of colonies were observed: a small type (colony diameter up to $0.5 \mathrm{~mm}$ ) and a large type (colony diameter up to $1 \mathrm{~mm}$ ). After $2 \mathrm{~d}$ growth, colonies of both types attained diameters of 1-2 mm. No haemolysis of sheep blood erythrocytes was noticed. Colonies appeared greyish-white, slightly crumbled and brittling during inoculation procedures.

Results of the biochemical reactions tested are given in the species description and Table 1. Utilization of different $\mathrm{C}$ sources was checked by the Biolog identification system (GN MicroPlate, release 3.5) and according to the Biolog system database, the species most similar to the new isolate was Comamonas terrigena. A detailed list of carbon sources used is provided in the species description. 
Table 1. Selected differential characteristics of Brackiella oedipodis and its nearest neighbours

Strains: 1, Brackiella oedipodis; 2, Bordetella avium; 3 , Bordetella parapertussis; 4, Alcaligenes faecalis subsp. faecalis; 5, Achromobacter xylosoxidans subsp. xylosoxidans; 6, Oligella urethralis; 7, Taylorella equigenitalis; 8, Pelistega europaea. + , More than $90 \%$ of strains positive; - , less than $10 \%$ of strains positive; $d$, strain-dependent reactions.

\begin{tabular}{|lcccccccc|}
\hline Characteristic & $\mathbf{1}$ & $\mathbf{2}$ & $\mathbf{3}$ & $\mathbf{4}$ & $\mathbf{5}$ & $\mathbf{6}$ & $\mathbf{7}$ & $\mathbf{8}$ \\
\hline Growth at $42{ }^{\circ} \mathrm{C}$ & - & + & - & + & $\mathrm{d}$ & + & + & + \\
Motility & - & + & - & + & + & - & - & - \\
Urease & - & - & + & - & - & - & - & $\mathrm{d}$ \\
$\mathrm{NO}_{3}^{-} \rightarrow \mathrm{NO}_{2}^{-}$ & + & - & - & - & + & - & - & - \\
Utilization of acetate & - & $\mathrm{d}$ & - & + & + & + & + & $\mathrm{ND}$ \\
\hline
\end{tabular}

ND, Not determined.

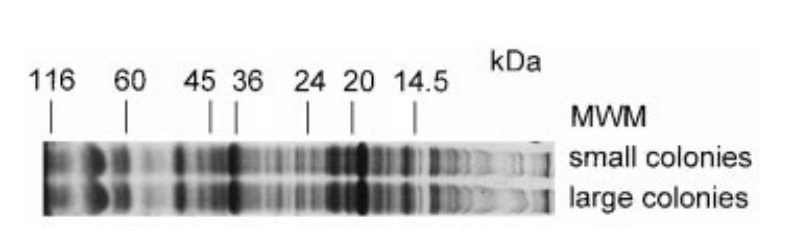

Fig. 2. SDS-PAGE protein profiles of the two colony types of the new isolate. MWM, Molecular mass markers.

\section{Analysis of proteins by SDS-PAGE}

Protein extracts were prepared from the two colony types of Brackiella oedipodis and comparison of their SDS-PAGE profiles (Fig. 2) revealed that these were identical. However, comparison of the protein patterns with those previously determined for various Comamonas strains (Willems et al., 1991) revealed little similarity with these organisms (data not shown).
Table 2. Fatty acid profile of the new isolate evaluated by the MIDI system

Closest match to Oligella ureolytica GC subgroup B (similarity index 0.363 , clinical aerobe database v. 3.8).

\begin{tabular}{|lcc|}
\hline Peak name & $\begin{array}{c}\text { Equivalent chain } \\
\text { length }\end{array}$ & $\begin{array}{c}\text { Fatty acid amount (\%) } \\
\text { (measured in triplicate) }\end{array}$ \\
\hline Unknown & $10 \cdot 622$ & $0 \cdot 78$ \\
$13: 1$ & $12 \cdot 934$ & $1 \cdot 86$ \\
$14: 1$ iso & $13 \cdot 387$ & $0 \cdot 22$ \\
$14: 0$ & $14 \cdot 000$ & $3 \cdot 80$ \\
$14: 0$ 3-OH & $15 \cdot 487$ & $5 \cdot 48$ \\
$16: 0$ & $16 \cdot 000$ & $23 \cdot 51$ \\
$16: 0$ 3-OH & $17 \cdot 518$ & $8 \cdot 02$ \\
$18: 1 \omega 7 c$ & $17 \cdot 823$ & $31 \cdot 45$ \\
$18: 1 \omega 5 c$ & $17 \cdot 918$ & $0 \cdot 48$ \\
$18: 0$ & $17 \cdot 999$ & $2 \cdot 13$ \\
$19: 0$ cyclo $\omega 8 c$ & $18 \cdot 901$ & $22 \cdot 29$ \\
\hline
\end{tabular}

\section{Analysis of 16S rDNA}

The newly determined 16S rDNA sequence consisted of $1473 \mathrm{nt}$. A FASTA search in the EMBL nucleic acid sequence database revealed the organism to be a member of the $\beta$-Proteobacteria. Its closest neighbours were the genera Taylorella, Pelistega, Alcaligenes, Achromobacter and Bordetella. The new sequence showed $92-93 \%$ homology to sequences of members of these genera retrieved from the EMBL database. A dendrogram showing the phylogenetic position of the isolate among these and related organisms is shown in Fig. 3.

\section{Siderophore production}

The isolate grew well on all of the cross-feeding plates tested but did not produce any growth zone of siderophore-indicator strains.

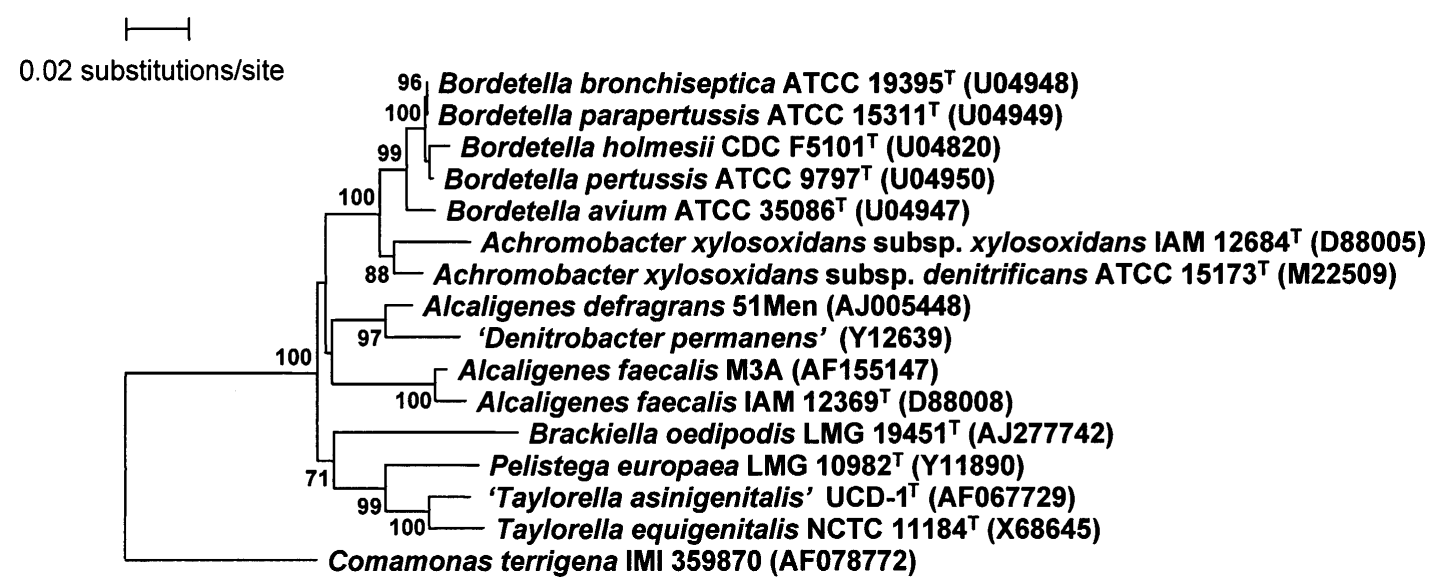

Fig. 3. Neighbour-joining dendrogram showing the position of the new isolate among its nearest neighbours in the $\beta$-Proteobacteria. Bootstrap values were expressed as a percentage of 500 replications and only values above $70 \%$ are shown at the branching points. 

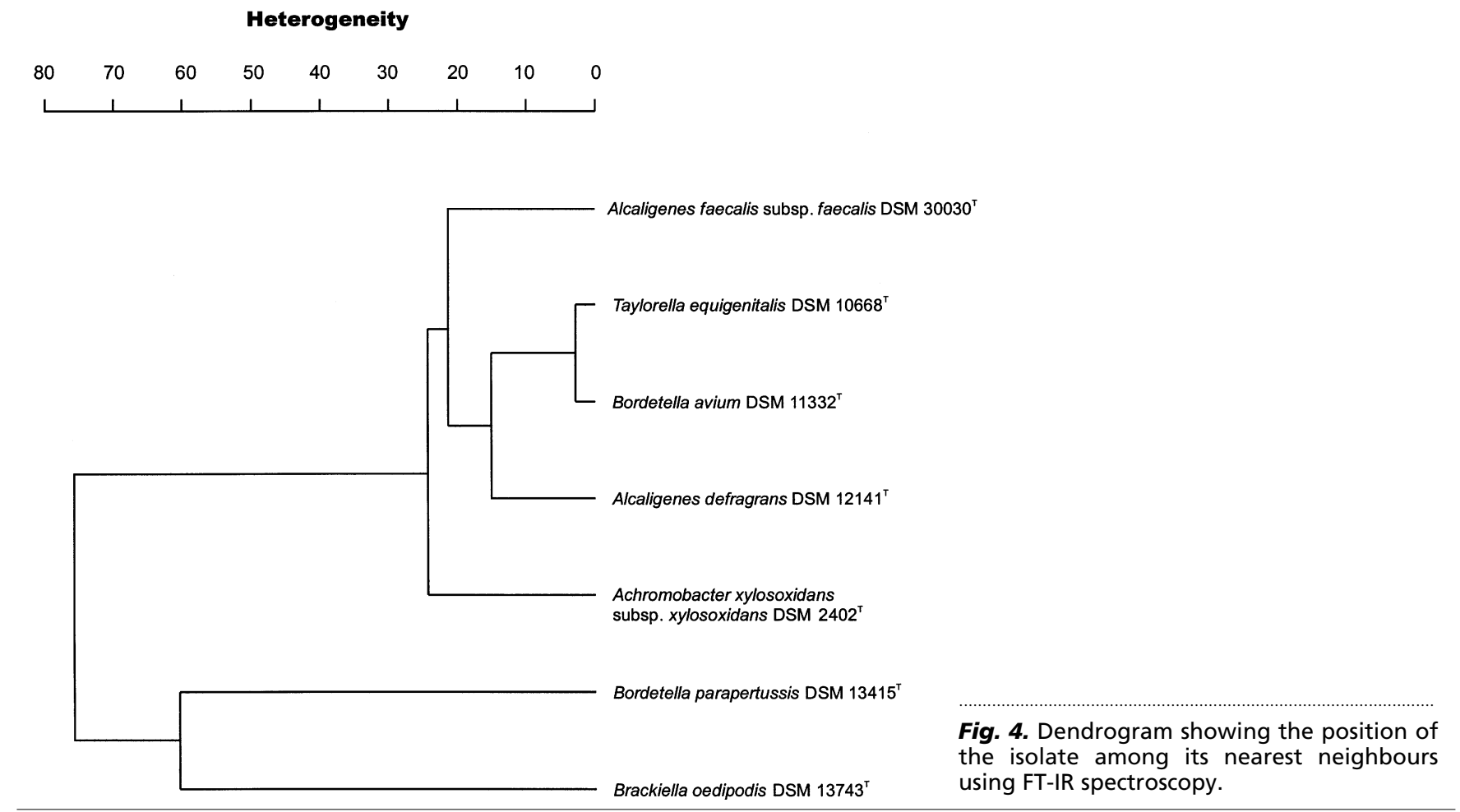

\section{Susceptibility to antimicrobial agents}

The isolate was susceptible to all of the following antimicrobials tested: amikacin, ampicillin, cefotaxime, cefotiam, cefoxitin, ceftazidime, chloramphenicol, ciprofloxacin, gentamicin, kanamycin, mezlocillin, mezlocillin/sulbactam, nalidixic acid, tetracycline, streptomycin, sulfamerazine and trimethoprim/sulfamerazine.

\section{Analysis of OMPs and IROMPs}

The new isolate produced one major OMP of $45 \mathrm{kDa}$ and a further three minor OMPs of lower molecular masses. Production of OMPs was reduced under irondepleted conditions; formation of higher amounts of three IROMPs of the typical molecular mass range (69-92 kDa) was observed. In contrast, Alcaligenes faecalis subsp. faecalis DSM $30030^{\mathrm{T}}$ produced significantly different OMPs and IROMPs compared to the new isolate. The major OMP exhibited a molecular mass of $38 \mathrm{kDa}$ and at least five IROMPs of the typical molecular mass range could be detected.

\section{Analysis of the LPS pattern}

The LPS pattern of the new isolate was different to that of Alcaligenes faecalis subsp. faecalis DSM $30030^{\mathrm{T}}$. Both species produced a ladder exhibiting repeating units of polysaccharide structures, but the patterns differed, particularly in the range $13-21 \mathrm{kDa}$. Additionally, the LPS pattern of Alcaligenes faecalis subsp. faecalis DSM $30030^{\mathrm{T}}$ differed in the presence of one strong band at $8.4 \mathrm{kDa}$, whereas the new isolate formed two bands in this region. The new isolate possessed further bands at 10 and $12 \mathrm{kDa}$ and additional minor bands in the range $21-26 \mathrm{kDa}$.

\section{Fatty acid profile}

No significant similarity to a known bacterial taxon could be detected using the libraries of the MIDI system to evaluate the fatty acid profile of the new isolate (Table 2). The closest match was Oligella ureolytica (similarity index 0.363 , clinical aerobe library), pointing to the genera Oligella, Taylorella, Alcaligenes or Bordetella (Rossau et al., 1987).

\section{FT-IR spectra}

FT-IR spectra were recorded for several bacterial strains representing taxa shown to be relatives of the new isolate by $16 \mathrm{~S}$ rDNA sequence analysis. Cluster analysis using the first derivatives of the FT-IR spectra is shown in Fig. 4. Results point to significant differences between the taxa studied.

\section{DISCUSSION}

A Gram-negative, oxidase-positive, rod-shaped bacterium was isolated from the heart of a cotton-topped tamarin that had died suddenly. Clinically relevant cardiac diseases are generally quite rare in non-human primates, although age-related myocardial fibrosis can be found and, in general, cardiopathology is frequently found in macaques as a result of experimental human/ simian immunodeficiency virus infections. Bacterial infections of the heart are, however, rarely observed in non-human primates. 
Upon isolation, two colony types on culture plates were obtained, but these were shown to represent the same strain by SDS-PAGE analysis of proteins (Fig. 2). Also, in biochemical tests both colony types behaved identically. The initial identification of the isolate by the Biolog system as $C$. terrigena (similarity $83.2 \%$ ) was not satisfactory for two reasons: i) a reliable species identification would need much greater similarity $(\geqslant 95 \%)$; and ii) C. terrigena has not been reported to be a causative agent of endo- or epicarditis. SDS-PAGE protein analysis also revealed no significant similarity with Comamonas strains (data not shown). Therefore, the nearly complete 16S rDNA sequence of the isolate was determined. Phylogenetic analysis revealed that the organism belongs to the $\beta$ Proteobacteria and is related to the genera Alcaligenes, Achromobacter, Bordetella, Taylorella and Pelistega. The sequence similarity with these taxa was 91.9$93.3 \%$ and, therefore, the new isolate forms a separate line of descent within this group (Fig. 3).

Distinctiveness of the new isolate from related members of the $\beta$-Proteobacteria is further corroborated by phenotypic and fatty acid analyses (Tables 1 and 2) and FT-IR spectroscopy (Fig. 4). Creation of a new genus and species, Brackiella oedipodis gen. nov., sp. nov., is therefore proposed for the tamarin isolate. It can be distinguished from its closest relatives by a number of basic phenotypic characteristics as listed in Table 1. Furthermore, production of acid from maltose and D-mannose by Brackiella oedipodis is also a significant difference. Achromobacter xylosoxidans subsp. xylosoxidans species utilize D-glucose and D-xylose (Kersters \& De Ley, 1984). In contrast, Brackiella oedipodis, as well as the other taxa listed in Table 1, do not use these carbohydrates.

Characterization of OMPs, IROMPs and LPS patterns clearly separate Brackiella oedipodis from Alcaligenes faecalis, Bordetella pertussis, pseudomonads and Enterobacteriaceae (Agiato \& Dyer, 1992; Anwar et al., 1991; Griffiths \& Williams, 1999; Hitchcock \& Brown, 1983). Although Brackiella oedipodis produced typical IROMPs responsible for transport of siderophores, no siderophores (catecholate-type, hydroxamate-type siderophores or $\alpha$-keto- $/ \alpha$-hydroxy acids tested) could be detected by the cross-feeding tests. The common siderophore-indicator strain Pseudomonas aeruginosa PAO 6609, additionally indicating pyoverdins and pyochelin produced from pseudomonads, also did not indicate any siderophore-mediated growth.

The Alcaligenaceae-Oligella-Taylorella rRNA cluster belongs to the $\beta$-Proteobacteria. The family Alcaligenaceae consists of the genera Alcaligenes and Bordetella (De Ley et al., 1986). Bordetella pertussis and Bordetella parapertussis are the causal agents of whooping cough in humans. Bordetella bronchiseptica, the causative agent of kennel cough in dogs, also causes bronchopneumonias in callitrichids, including cottontopped tamarins. Bordetella avium is the causal agent of rhinotracheitis in turkey poults (Kersters et al., 1984). Extensive phenotypic and genotypic data have shown that two other genera, Oligella and Taylorella, are neighbours of the family Alcaligenaceae (Rossau et al., 1987). Oligella strains appear as small, fastidious rods which only use a few organic and amino acids and are otherwise biochemically rather inert. Oligella urethralis strains are mainly isolated from human urine; their pathogenicity is unknown (Rossau et al., 1987). T. equigenitalis is the causal agent of endometritis and cervicitis in mares. Pelistega europaea, the main causative agent of infections of the respiratory tract of pigeons is a close phylogenetic neighbour of $T$. equigenitalis. Pelistega europaea differs significantly from Brackiella by $16 \mathrm{~S}$ rDNA analysis (Fig. 3) and by the characteristics listed in Table 1. Dyson et al. (1999) summarized 128 cases of endocarditis in humans. Members of the Alcaligenaceae or related genera were not detected in any of these. Therefore, Brackiella oedipodis is the first member of this phylogenetic group to be associated with endocarditis. Its source and route of transmission are unknown at present.

\section{Description of Brackiella gen. nov.}

Brackiella (Bra'cki.ella. L. n. Brackiella in honour of Manfred Brack, German pathologist, head of the Department of Pathology of the Deutsches Primatenzentrum GmbH, Göttingen, from 1978 to 1999).

Cells are coccoid, $0.9 \times 1.1 \mu \mathrm{m}$ and surrounded by densely studded fimbriae $280 \mathrm{~nm}$ in length. They are non-motile, Gram-negative and oxidase-positive. Aerobic to microaerophilic, as shown by improved growth in the atmosphere of a candle jar. Chemoorganotrophic. Good growth at temperatures of 30 $37^{\circ} \mathrm{C}$. Catalase-positive, urease-negative, nitrate reduced to nitrite. Major fatty acids found are palmitic acid (16:0), vaccenic acid (18:1), lactobacillic acid (19:0 cyclo) and 3-hydroxypalmitic acid (16:0 3-OH). Brackiella belongs to the $\beta$-Proteobacteria and is related to the genera Alcaligenes, Achromobacter, Bordetella, Taylorella and Pelistega. Phenotypic features for the discrimination of these taxa are given in Table 1. Type species is Brackiella oedipodis.

\section{Description of Brackiella oedipodis sp. nov.}

Brackiella oedipodis (oe.di.po'dis. N.L. gen. n. oedipodis referring to the first isolation source, the tamarin Saguinus oedipus).

The description of Brackiella oedipodis is the same as that given for the genus. Colonies on tryptic soy blood agar are greyish-white, slightly rough with a diameter of $1-2 \mathrm{~mm}$ after $2 \mathrm{~d}$ growth at $37^{\circ} \mathrm{C}$ with no haemolysis. Similar growth observed on tryptic soy agar (light-white colonies of the same size), bile-chrysoidinglycerol agar according to Ziesché et al. (1985) (greenblue colonies of about $1 \mathrm{~mm}$ in diameter), King A agar (no pigmentation and no fluorescence under UV $365 \mathrm{~nm}$ ), Tween 80 agar, gelatinase agar, starch agar, CDM-H agar (a chemically defined medium; Flossmann et al., 1984). Good growth in nutrient broth and in tryptic soy broth at $37^{\circ} \mathrm{C}$ for $24 \mathrm{~h}$. No growth on 
MacConkey agar, King B agar, cetrimide agar, acetamide agar, milk agar or in $6.5 \% \mathrm{NaCl}$ broth. Grows at temperatures of $30-37^{\circ} \mathrm{C}$, but not at 4,20 or $42{ }^{\circ} \mathrm{C}$. The following biochemical tests are positive: Lalanine aminopeptidase, methyl red, ornithine decarboxylase, hydrolysis of starch, and production of acid from D-mannose and maltose. The following biochemical characteristics are negative: indole production, Voges-Proskauer, Simmon's citrate, $\mathrm{H}_{2} \mathrm{~S}$ (Kligler) production, phenylalanine deaminase, lysine decarboxylase, arginine dihydrolase, growth on $\mathrm{KCN}$, aesculin hydrolysis, Tween 80 hydrolysis, DNase, lipase, gelatinase, $\beta$-D-galactosidase, pyrase, $\beta$-D-glucuronidase, yellow pigment production, use of malonate, tartrate (Jordan) or acetate, production of gas or acid from glucose, and production of acid from methyl $\alpha$-D-glucoside, adonitol, cellobiose, D-sorbitol, dulcitol, D-xylose, erythritol, glycerol, lactose, L-arabinose, L-rhamnose, mannitol, melibiose, mucate, myo-inositol, raffinose, saccharose, salicin and trehalose. Carbon sources utilized using the Biolog system were (measured after $3 \mathrm{~d}$ at $37^{\circ} \mathrm{C}$ ): Tween 40 , Tween 80 , methyl pyruvate, cis-aconitic acid, formic acid, $\alpha$-hydroxybutyric acid, $\beta$-hydroxybutyric acid, $\gamma$-hydroxybutyric acid, $\alpha$-ketobutyric acid, $\alpha$-ketoglutaric acid, $\alpha$-ketovaleric acid, DL-lactic acid, sebacic acid, succinic acid, bromosuccinic acid, succinamic acid, D-alanine, Lglutamic acid, glycyl-L-glutamic acid and L-serine. Susceptible to the following antimicrobial agents: amikacin, ampicillin, cefotaxime, cefotiam, cefoxitin, ceftazidime, chloramphenicol, ciprofloxacin, gentamicin, kanamycin, mezlocillin, mezlocillin/sulbactam, nalidixic acid, tetracycline, streptomycin, sulfamerazine and trimethoprim/sulfamerazine. Isolated from the heart of a cotton-topped tamarin that had died suddenly during a tooth extraction. The heart showed clear signs of endocarditis for which Brackiella oedipodis may be the causal agent. Type strain, and so far the only strain reported, is LMG $19451^{\mathrm{T}}$ (= DSM $13743^{\mathrm{T}}=$ NCIMB $13739^{\mathrm{T}}$ ).

\section{ACKNOWLEDGEMENTS}

The authors thank Manfred Brack, Deutsches Primatenzentrum Göttingen, Germany, who was responsible for the pathological investigations. A.W. is grateful to the Fund for Scientific Research-Flanders for a position as Postdoctoral Research Fellow. We are grateful to Freya Kaulbars, Robert Koch-Institute Berlin, for reliable negative staining electron microscopy. The authors are very indebted to Derwent Swaine, Oxford, UK, for critical reading of the manuscript.

\section{REFERENCES}

Achtman, M., Mercer, A., Kusecek, A., Pohl, A., Heuzenroeder, M., Aaronson, W., Sutton, A. \& Silver, R. P. (1983). Six widespread bacterial clones among Escherichia coli $\mathrm{K} 1$ isolates. Infect Immun 39, 315-335.

Agiato, L. A. \& Dyer, D. W. (1992). Siderophore production and membrane alterations by Bordetella pertussis in response to iron starvation. Infect Immun 60, 117-123.

Anwar, H., Strap, J. L. \& Costerton, J. W. (1991). Growth characteristics and expression of iron regulated outer-mem- brane proteins of chemostat-grown biofilm cells of Pseudomonas aeruginosa. Can J Microbiol 37, 737-743.

De Ley, J., Segers, P., Kersters, K., Mannheim, W. \& Lievens, A. (1986). Intra- and intergeneric similarities of the Bordetella ribosomal ribonucleic acid cistrons: proposal for a new family Alcaligenaceae. Int J Syst Bacteriol 36, 405-414.

Devereux, J., Haeberli, P. \& Smithies, O. (1984). A comprehensive set of sequence analysis programs for the VAX. Nucleic Acids Res 12, 387-395.

Dyson, C., Barnes, R. A. \& Harrison, G. A. J. (1999). Infective endocarditis: an epidemiological review of 128 episodes. $J$ Infect 38, 87-93.

Flossmann, K.-D., Rosner, H., Grünke, U. \& Miosga, N. (1984). Beeinflussung der Virulenz und Immunogenität bei Pasteurella multocida durch Eisen in vitro. Z Allg Mikrobiol 24, 231-237.

Gelderblom, H., Beutin, L., Hadjiyannis, D. \& Reupke, H. (1985). Rapid typing of pathogenic Escherichia coli by dispersive immunoelectron microscopy. In Rapid Methods and Automation in Microbiology and Immunology, pp. 390-400. Edited by K.-O. Habermehl. New York: Springer.

Griffiths, E. \& Williams, P. (1999). The iron-uptake systems of pathogenic bacteria, fungi and protozoa. In Iron and Infection, 2nd edn, pp. 87-212. Edited by J. J. Bullen \& E. Griffith. Chichester: Wiley.

Helm, D., Labischinski, H., Schallehn, G. \& Naumann, D. (1991). Classification and identification of bacteria by Fourier-transform infrared spectroscopy. J Gen Microbiol 137, 69-79.

Hitchcock, P. J. \& Brown, T. M. (1983). Morphological heterogeneity among Salmonella lipopolysaccharide chemotypes in silver-stained polyacrylamide gels. J Bacteriol 154, 269-277.

Kersters, K. \& De Ley, J. (1984). Genus Alcaligenes Castellani and Chalmers 1919, 936. In Bergey's Manual of Systematic Bacteriology, vol. 1, pp. 361-373. Edited by N. R. Krieg \& J. G. Holt. Baltimore: Williams \& Wilkins.

Kersters, K., Hinz, K.-H., Hertle, A., Segers, P., Lievens, A., Siegmann, O. \& De Ley, J. (1984). Bordetella avium sp. nov., isolated from the respiratory tracts of turkeys and other birds. Int J Syst Bacteriol 34, 56-70.

Lugtenberg, B., Meijers, J., Peters, R., van der Hoek, P. \& van Alphen, L. (1975). Electrophoretic resolution of the "major outer membrane protein' of Escherichia coli K12 into four bands. FEBS Lett 58, 254-258.

Murray, P. R., Baron, E. J., Pfaller, M. A., Tenover, F. C. \& Yolken, R. H. (1999). Manual of Clinical Microbiology, 7 th edn. Washington, DC: American Society for Microbiology.

National Committee for Clinical Laboratory Standards (1998). Performance standards for antimicrobial susceptibility testing; eight informational supplement. M100-S8. Villanova, PA: National Committee for Clinical Laboratory Standards

Pot, B., Vandamme, P. \& Kersters, K. (1994). Analysis of electrophoretic whole-organism protein fingerprints. In Modern Microbial Methods (Chemical Methods in Prokaryotic Systematics Series), pp. 493-521. Edited by M. Goodfellow \& A. G. O'Donnell. Chichester: Wiley.

Reissbrodt, R., Heinisch, L., Möllmann, U., Rabsch, W. \& Ulbricht, H. (1993). Growth promotion of synthetic catecholate derivatives on Gram-negative bacteria. Biometals 6, 155-162.

Reissbrodt, R., Kingsley, R., Rabsch, W., Beer, W., Roberts, M. \& Williams, P. H. (1997). Iron-regulated excretion of $\alpha$-keto acids by Salmonella typhimurium. J Bacteriol 179, 4538-4544.

Rossau, R., Kersters, K., Falsen, E., Jantzen, E., Segers, P., Union, A., Nehls, L. \& De Ley, J. (1987). Oligella, a new genus including 
Oligella urethralis comb. nov. (formerly Moraxella urethralis) and Oligella ureolytica sp. nov. (formerly CDC group IVe): relationships to Taylorella equigenitalis and related taxa. Int $J$ Syst Bacteriol 37, 198-210.

Tsai, C.-M. \& Frasch, C. E. (1982). A sensitive silver stain for detecting lipopolysaccharides in polyacrylamide gels. Anal Biochem 119, 115-119.

Vandamme, P., Segers, P., Ryll, M. \& 8 other authors (1998). Pelistega europaea gen. nov., sp. nov., a bacterium associated with respiratory disease in pigeons: taxonomic structure and phylogenetic allocation. Int J Syst Bacteriol 48, 431-440.

Van de Peer, Y. \& De Wachter, R. (1994). TREECON for Windows: a software package for the construction and drawing of evolutionary trees for the Microsoft Windows environment. Comput Appl Biosci 10, 569-570.

Willems, A., Pot, B., Falsen, E., Vandamme, P., Gillis, M., Kersters, K. \& De Ley, J. (1991). Polyphasic taxonomic study of the emended genus Comamonas: relationship to Aquaspirillum aquaticum, E. Falsen Group 10, and other clinical isolates. Int J Syst Bacteriol 41, 427-444.

Ziesché, K., Reissbrodt, R. \& Rische, H. (1985). Der GalleChrysoidin-Glycerol(GCG)-Nährboden in seiner Anwendung zur Diagnostik gramnegativer Bakterien, besonders der Enterobacteriaceae. Z Gesamte Hyg 31, 516-518. 